SANTOS, O.S. et al. Forrageiras hidropônicas de trigo com ervilhacas. PUBVET, Londrina, V. 6, N. 9, Ed. 196, Art. 1317, 2012.

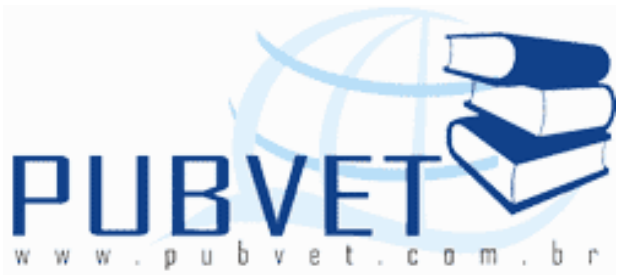

PUBVET, Publicações em Medicina Veterinária e Zootecnia.

\title{
Forrageiras hidropônicas de trigo com ervilhacas
}

\section{Osmar Souza dos Santos ${ }^{1}$, Alfredo do Nascimento Junior ${ }^{2}$, Denise Puntel} Basso $^{3}$, Alberto Cargnelutti Filho ${ }^{4}$, Jorge Eugênio Filipetto ${ }^{5}$, Rodrigo da Costa Luz $^{6}$, Francisco Roberto Souilljee ${ }^{7}$

${ }^{1}$ Engenheiro Agrônomo, Doutor, Professor Colaborador do Colégio Politécnico da Universidade Federal de Santa Maria (UFSM). Pesquisador do CNPq. 97105900, Santa Maria, RS. osmarsouzasantos@gmail.com

2 Engenheiro Agrônomo, Doutor, Pesquisador da Embrapa-Trigo. 99001-970, Passo Fundo, RS. alfredo@cnpt.embrapa.br

${ }^{3}$ Engenheira Agrônoma da UFSM. denisepbasso@gmail.com

${ }^{4}$ Engenheiro Agrônomo, Doutor, Professor do Departamento de Fitotecnia da UFSM. alberto.cargnelutti.filho@gmail.com

${ }^{5}$ Técnico do Colégio Politécnico da UFSM. jorgefilipetto@gmail.com

${ }^{6}$ Acadêmico da UFSM. rodrigodacostaluz@yahoo.com.br

${ }^{7}$ Engenheiro Agrônomo, Sementes Souilljee, Carazinho, RS.

\section{Resumo}

O experimento foi realizado no Colégio Politécnico da Universidade Federal de Santa Maria (UFSM) - Rio Grande do Sul, com o objetivo de avaliar a produção de forrageira hidropônica de trigo BRS Tarumã (Triticum aestivum L.) na densidade de $2,0 \mathrm{~kg} \mathrm{~m}^{-2}$, associada com quatro densidades das cultivares ervilhaca comum SS Ametista (Vicia sativa L.) e ervilhaca peluda SS Esmeralda 
SANTOS, O.S. et al. Forrageiras hidropônicas de trigo com ervilhacas. PUBVET, Londrina, V. 6, N. 9, Ed. 196, Art. 1317, 2012.

(Vicia villosa Roth) nas doses de 0,150, 300 e $450 \mathrm{~g} \mathrm{~m}^{-2}$, no período de 15 a 30 de setembro de 2011. O experimento foi conduzido em túnel alto com cada tratamento em área de $1,0 \mathrm{~m}^{-2}$, utilizando-se solução nutritiva descrita por Santos et al. (2004). As avaliações referentes a produção de massa fresca foram realizadas aos 16 dias após a semeadura. As maiores produtividades obtidas pelo trigo foram $15,100 \mathrm{~kg} \mathrm{~m}^{-2}$, equivalente a $151 \mathrm{t} \mathrm{ha}^{-1}$, sem a presença das ervilhacas.

Palavras-chave: hidroponia, forrageiras, trigo, SS Ametista, SS Esmeralda.

\section{Production of hydroponic fodder of wheat with common vetch}

\section{Abstract}

An experiment was conducted at the Colégio Politécnico da Universidade Federal de Santa Maria (UFSM) - RS, in order to evaluate the production of hydroponic fodder of wheat BRS Tarumã (Triticum aestivum L.) at the densities $2.0 \mathrm{~kg} \mathrm{~m}^{-2}$, associated with four densities of commom vetch, SS Ametista (Vicia sativa L.) and hairy vetch, SS Esmeralda (Vicia villosa Roth), at doses of $0,150,300$ and $450 \mathrm{~g} \mathrm{~m}^{-2}$, during the winter of 2011 . The experiment was conducted in a high tunnel with each treatment in an area of $1.0 \mathrm{~m}^{-2}$, using a nutrient solution described by Santos et al. (2004). Evaluations were performed at 16 days after sowing. The highest yield was obtained by wheat without vetches varieties.

Keywords: hydroponics, forage, wheat, hairy vetch, commom vetch.

\section{INTRODUÇÃO}

No outono, no inverno e na primavera, no sul do Brasil, ocorrem deficiência nas pastagens por causa das baixas temperaturas, geadas e excessos de chuvas.

Para suprir a deficiência das pastagens naturais é indicada a produção de pastagens realizadas na hidroponia. O cultivo de forragem hidropônica é uma 
SANTOS, O.S. et al. Forrageiras hidropônicas de trigo com ervilhacas. PUBVET, Londrina, V. 6, N. 9, Ed. 196, Art. 1317, 2012.

tecnologia de produção de biomassa vegetal obtida através da germinação e desenvolvimento inicial das plantas a partir de sementes viáveis, de alta digestibilidade e qualidade nutricional (FAO, 2001).

A produção das forrageiras hidropônicas tem como vantagens a eliminação do uso de defensivos agrícolas, uma vez que não ocorrem invasoras prejudiciais, doenças e pragas no sistema, ciclo de produção mais rápido, independência das mudanças nas condições climáticas ao longo do ano, maior produtividade por unidade de área, redução da mão de obra, redução das tarefas inerentes à produção e conservação de forragens (silagem, fenação), economia e melhor aproveitamento dos fertilizantes, liberação de área para uso com outras culturas e uso de diferentes espécies vegetais (SANTOS et al., 2002).

O cultivo de forragem hidropônica é irrigado com solução nutritiva, sem a necessidade do uso de solo. Em vários países e inclusive no Brasil, a forragem hidropônica vem sendo utilizada com êxito para suplementação da dieta de animais, como bovinos de leite e de corte, cavalos, cordeiros, cabras e coelhos (SANTOS et al., 2006).

Entre as várias espécies vegetais que podem ser utilizadas para produção de forragens hidropônicas cabe destaque ao trigo, que vêm sendo estudado há vários anos, com destaque para a pesquisa que comparou duas soluções nutritivas: Neves (2001) com 105,9 $\mathrm{mg} \mathrm{L}^{-1}$ de nitrogênio (N) e a solução nutritiva proposta por Santos et al. (2004) com 190,6 $\mathrm{mg} \mathrm{L}^{-1} \mathrm{~N}$; e quatro idades de colheita (4, 8, 12 e 16 dias após a semeadura). O resultado demonstrou que a solução Santos et al. (2004) foi mais produtiva que a Neves (2001), bem como a indicação de colheita para 12 a 16 dias após a semeadura (MÜLLER et al., 2006).

Esta pesquisa teve como objetivo avaliar a produção da cultivar de trigo BRS Tarumã em hidroponia associada com quatro densidades de ervilhacas comum e peluda. 
SANTOS, O.S. et al. Forrageiras hidropônicas de trigo com ervilhacas. PUBVET, Londrina, V. 6, N. 9, Ed. 196, Art. 1317, 2012.

\section{MATERIAL E MÉTODOS}

O experimento foi realizado no Colégio Politécnico da Universidade Federal de Santa Maria - RS, com coordenadas geográficas: latitude 29042'S, longitude 53043'W e altitude $95 \mathrm{~m}$.

As variedades foram conduzidas em um túnel alto com $6 \mathrm{~m}$ de largura e $30 \mathrm{~m}$ de comprimento (Figura 1), disposto no sentido norte-sul, coberto com polietileno de baixa densidade (PEBD) com espessura de $150 \mu$, aditivado contra raio ultravioleta. Os canteiros foram confeccionados com filme plástico (lona preta de $100 \mu$ de espessura), estendidos sobre o solo nivelado, sendo as bordas limitadas por guias de madeira com $6,0 \mathrm{~cm}$ de altura, formando parcelas de $1,0 \mathrm{~m}^{2}$. Antes da semeadura, foi realizada a técnica de prégerminação que consistiu na embebição das sementes em água por 24 horas (SANTOS et al., 2006). Logo após, foram semeadas de acordo com cada tratamento.

As semeaduras foram realizadas no dia 15 de setembro e as colheitas no dia 30 de setembro de 2011, com um período de 16 dias.

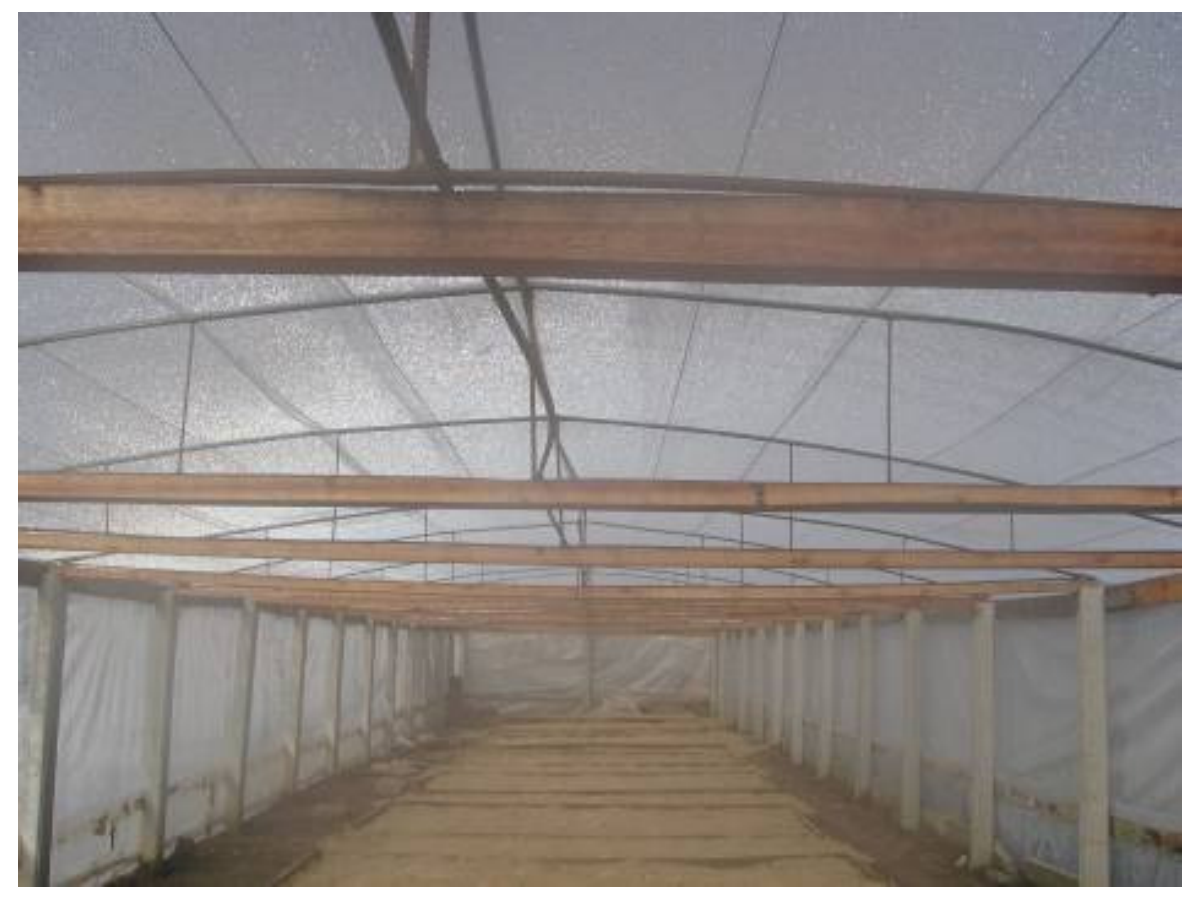

Figura 1. Túnel alto com $6 \mathrm{~m}$ de largura e $30 \mathrm{~m}$ de comprimento. 
SANTOS, O.S. et al. Forrageiras hidropônicas de trigo com ervilhacas. PUBVET, Londrina, V. 6, N. 9, Ed. 196, Art. 1317, 2012.

Foi utilizada a cultivar de trigo BRS Tarumã (Triticum aestivum L.) na densidade de $2,0 \mathrm{~kg} \mathrm{~m}^{-2}$, associada com quatro densidades das cultivares ervilhaca comum SS Ametista (Vicia sativa L.) e ervilhaca peluda SS Esmeralda (Vicia villosa Roth) nas doses de 0, 150, 300 e $450 \mathrm{~g} \mathrm{~m}^{-2}$ (Figuras 2 e 3).

As plantas receberam solução nutritiva especial para produção de forrageiras (SANTOS et al., 2004). Aos 16 dias da semeadura foi feita a coleta e a pesagem de quatro amostras de $0,20 \times 0,20 \mathrm{~m}$ de todos os tratamentos.

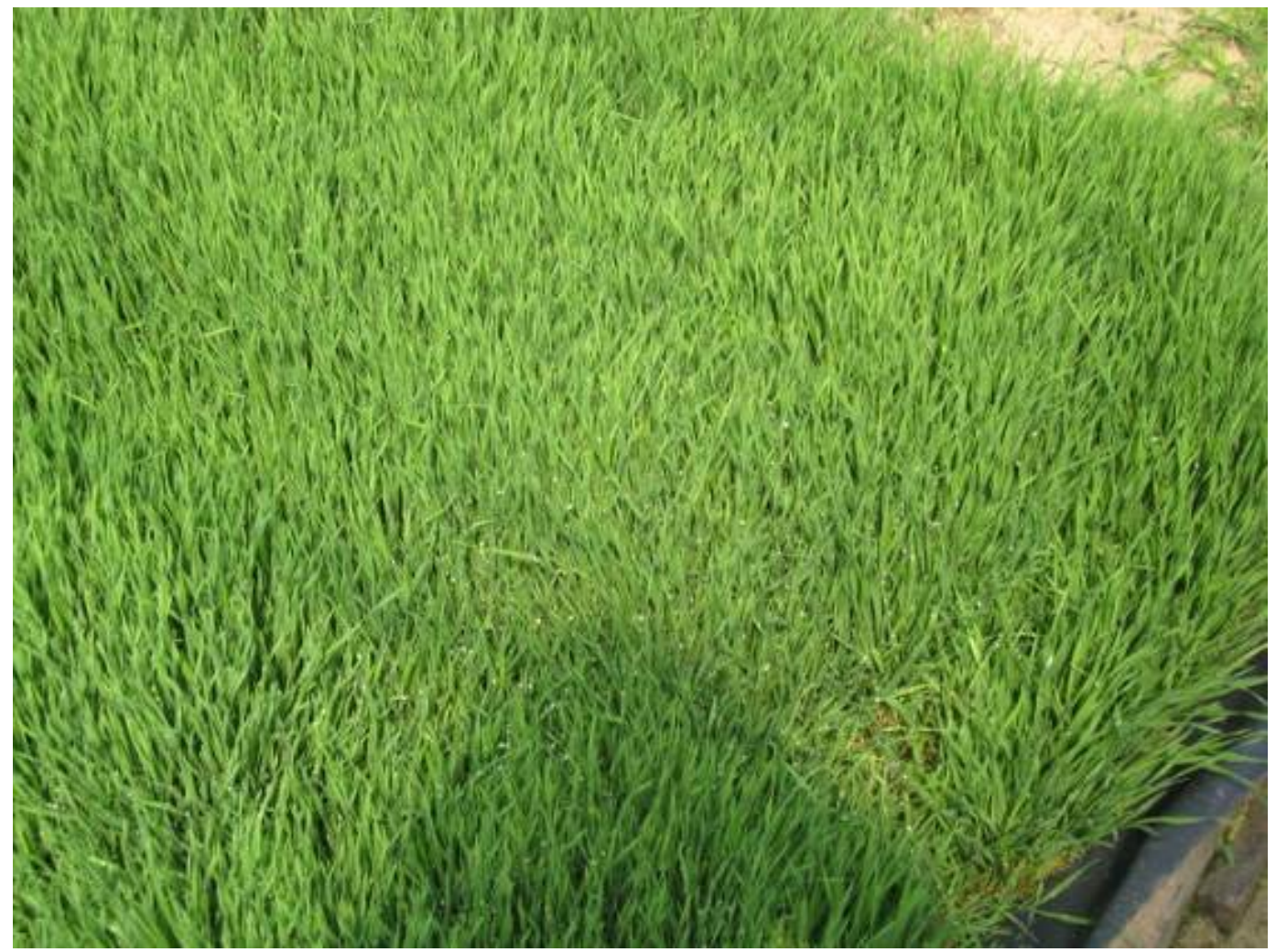

Figura 2. Trigo BRS Tarumã $\left(2,0 \mathrm{~kg} \mathrm{~m}^{-2}\right)$ cultivado sem ervilhacas. 
SANTOS, O.S. et al. Forrageiras hidropônicas de trigo com ervilhacas. PUBVET, Londrina, V. 6, N. 9, Ed. 196, Art. 1317, 2012.

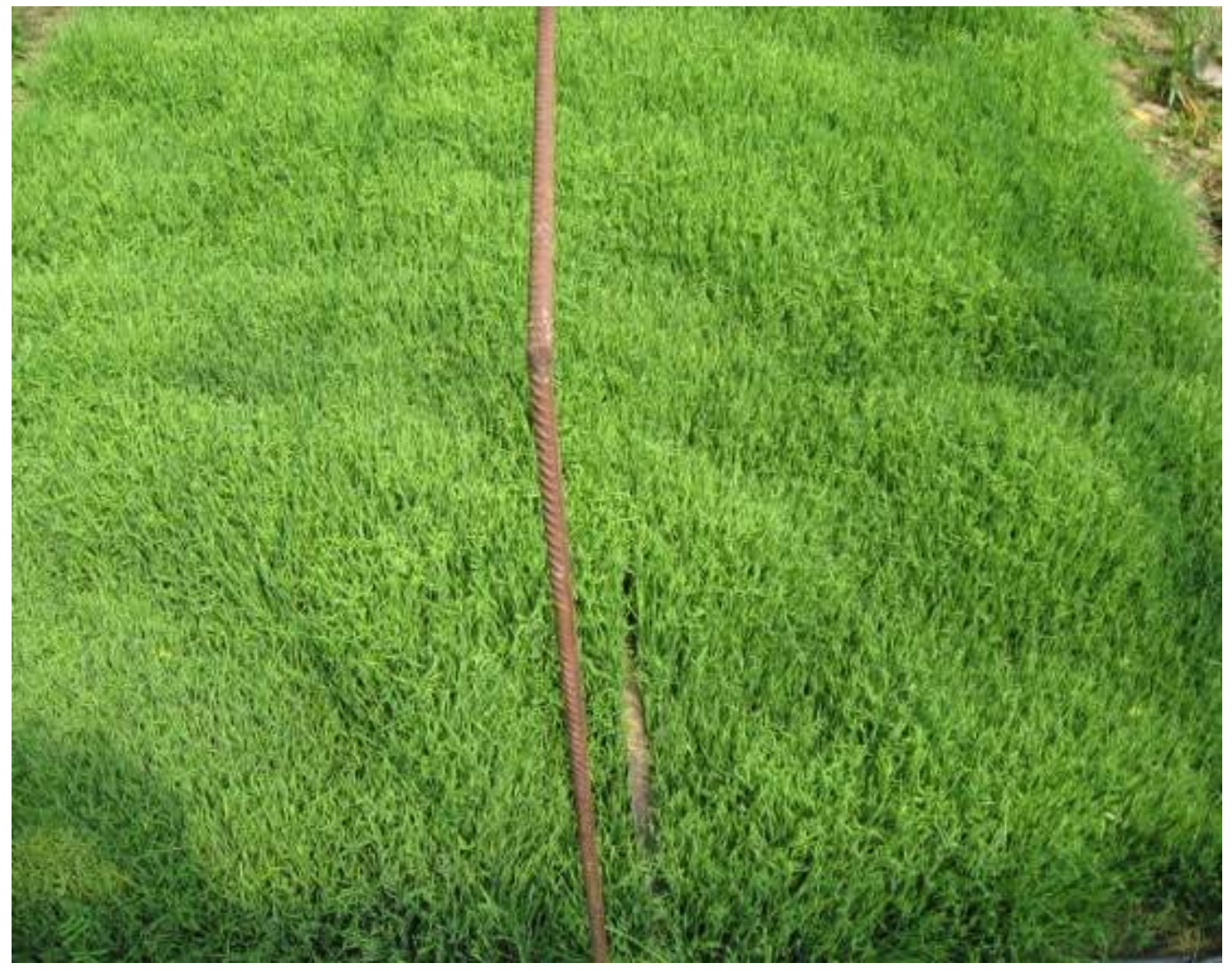

Figura 3. Trigo BRS Tarumã $\left(2,0 \mathrm{~kg} \mathrm{~m}^{-2}\right)$ cultivado com ervilhacas.

\section{RESULTADOS E DISCUSSÃO}

Os resultados obtidos nas pesagens das amostras de $0,20 \mathrm{~m} \times 0,20 \mathrm{~m}$, em $\mathrm{g} \mathrm{m}^{-2}$, foram transformados em $\mathrm{kg} \mathrm{m}^{-2} \mathrm{e} \mathrm{kg} \mathrm{ha}^{-1}$.

As avaliações das doses de ervilhaca comum e ervilhaca peluda demonstraram que não houve reação positiva no aumento de $0,150,300 \mathrm{e}$ $450 \mathrm{~g} \mathrm{~m}^{-2}$ (Figura 4).

A maior produção, na média, foi do trigo BRS Tarumã $\left(2,0 \mathrm{~kg} \mathrm{~m}^{-2}\right)$ isolado das ervilhacas (Figura 4), realizado no Colégio Politécnico da Universidade Federal de Santa Maria (UFSM) - Rio Grande do Sul, com o objetivo. Isso indica que as ervilhacas, com todas as suas doses, não conseguiram aumentar a produção de massa fresca, de modo que a produção dessas forrageiras deve ser feita apenas com a semeadura do trigo. 
SANTOS, O.S. et al. Forrageiras hidropônicas de trigo com ervilhacas. PUBVET, Londrina, V. 6, N. 9, Ed. 196, Art. 1317, 2012.

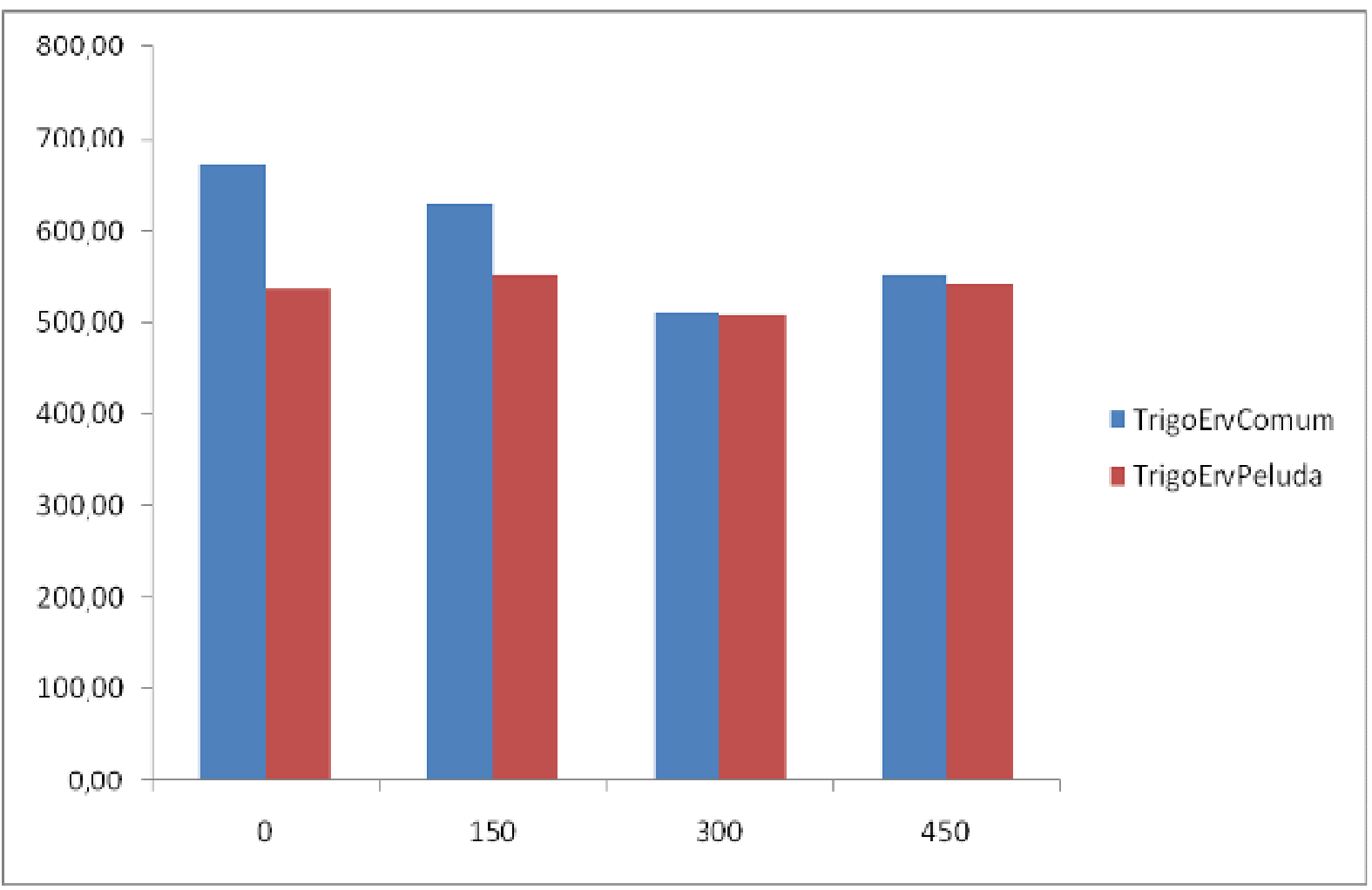

Figura 4. Produção média de massa verde das amostras $(20 \mathrm{~cm} \times 20 \mathrm{~cm})$ de trigo $\left(2 \mathrm{~kg} \mathrm{~m}^{-2}\right)$ sem e com as ervilhacas comum e peluda $(0,150,300$ e $450 \mathrm{~g}$ $\left.\mathrm{m}^{-2}\right)$.

\section{CONCLUSÕES}

A cultivar de trigo BRS Tarumã, com $2 \mathrm{~kg} \mathrm{~m}^{-2}$, é mais produtiva sem a presença das ervilhacas comum e peluda.

As doses das ervilhacas de 150, 300 e $450 \mathrm{~g} \mathrm{~m}^{-2}$, em associação com BRS Tarumã, não aumentam a produtividade.

\section{REFERÊNCIAS BIBLIOGRÁFICAS}

FAO. Manual técnico forraje verde hidropônico. Santiago, 2001. v.1, 73p.

SANTOS, O.S.; MANFRON, P.A.; MÜLLER, L.; MEDEIROS, S.L.P.; TONETTO, C.J.; BANDEIRA, A.H.; DUARTE, T.S.; LUZ, G.L.; BORCIONI, E. Produção e qualidade nutricional da forragem hidropônica. Informe Técnico. Santa Maria: UFSM/CCR, 2006, 8p. (34/2006). 
SANTOS, O.S.; MÜLLER, L.; PIRES, C.; TONETTO, C.J.; MEDEIROS, S.L.P.; FRESCURA, R.B.N.; HAUT, V.; SILVA, D.V.R. Produção de forragem hidropônica de cevada e milho e seu uso na alimentação de cordeiros. Informe Técnico. Santa Maria: UFSM/CCR, 2004, 8p. (04/2004).

SANTOS, O.S.; SCHMIDT, D.; NOGUEIRA FILHO, H.; LONDERO, F.A. Produção de forragem hidropônica. In:_. Cultivos sem solo: hidroponia. 2a. Reimpressão. Santa Maria: UFSM/CCR, 2002, p.94-98. (Caderno Didático, 01).

MÜLLER, L.; MANFRON, P.A.; MEDEIROS, S.L.P.; SANTOS, O.S.; MORSELLI, T.B.G.A.; DOURADO NETO, D.; FAGAN, E.B.; BANDEIRA, A.H.; TONETTO, C.J. Valor nutricional da forragem hidropônica de trigo sob diferentes soluções nutritivas. Biosci. J., Uberlândia, v.22, n.3, p.49-56, Sept./Dec. 2006.

MÜLLER, L.; MANFRON, P.A.; SANTOS, O.S.; MEDEIROS, S.L.P; DOURADO NETO, D.; FAGAN, E.B.; BANDEIRA, A.H.; BORCIONI, E. Custo de produção da forragem hidropônica de trigo cultivada com duas soluções nutritivas. Rev. Científica Rural, v.10, n.2, p.108-115, 2005.

NEVES, A.L.R.A. Cultivo de milho hidropônico para alimentação animal. Viçosa: CPT, 2001. 46p. 